\title{
GAMBARAN PSIKOLOGIS INDIVIDU DENGAN KECENDERUNGAN KLEPTOMANIA
}

\author{
Bangkit Ary Prabowo, Karyono \\ Fakultas Psikologi Universitas Diponegoro \\ Jl. Prof. Soedharto SH, Tembalang, Semarang 50275 \\ karyonoundip@yahoo.com
}

\begin{abstract}
Kleptomania is the inability to refrain from the urge to steal items and is done for reasons other than personal use or financial gain. Alternatively, some of the main characteristics of the disorder, which consist of recurring intrusion feelings, an inability to resist the urge to steal, and a release of pressure following the theft, suggest that kleptomania could be an obsessive-compulsive spectrum disorder. Persons diagnosed with kleptomania usually gain satisfaction after his stolen activity was done. This study is a qualitative-phenomenological study. Two men involved in the study; both subjects had been encountered an impulse disorder for years. The results showed that both subjects made plans before they stole things. They had an ego defense mechanism against kleptomania impulse that emerged when there are external and internal factors that weaken their wishes. Subject who has a good ego defense mechanism, have a strong will to recover; however, subject who has a weak ego defense mechanism will have a weak will to recover.
\end{abstract}

Keywords: kleptomania, ego defense mechanism, phenomenology

\begin{abstract}
Abstrak
Kleptomania merupakan sebuah tindakan pengambilan barang yang didasari oleh impuls atau dorongan sebagai sarana pemenuhan kepuasan. Pelaku kleptomania biasanya mendapatkan kepuasan setelah melakukan tindakannya. Penelitian ini merupakan penelitian kualitatif dengan menggunakan pendekatan fenomenologi. Subjek terdiri dari dua orang laki-laki yang memiliki kecenderungan untuk melakukan pengambilan barang secara sembunyi-sembunyi. Kedua subjek telah memiliki gangguan pengendalian impuls selama bertahun-tahun dan sudah sangat sering melakukan perbuatannya. Hasil penelitian ini menunjukkan bahwa kedua subjek memiliki perencanaan ketika akan melakukan perbuatannya. Mereka pada dasarnya memiliki mekanisme pertahanan diri terhadap impuls kleptomania yang muncul apabila ada faktor yang melemahkan niatannya, baik faktor eksternal maupun internal. Tingkat mekanisme pertahanan diri yang dimiliki subjek sangat mempengaruhi keinginannya untuk sembuh. Subjek yang memiliki mekanisme pertahanan diri baik, memiliki keinginan sembuh yang tinggi; sedangkan subjek yang memiliki mekanisme pertahanan diri yang rendah, kurang memiliki keinginan untuk sembuh.
\end{abstract}

Kata kunci: kleptomania, mekanisme pertahanan ego, fenomenologi

\section{PENDAHULUAN}

Fenomena tentang terjadinya pencurian merupakan suatu tindak pidana yang tidak asing lagi terdengar. Pencurian termasuk didalam tindak pidana kejahatan. Pernyataan tersebut senada dengan yang dijelaskan oleh Prayudi (2008), bahwa contoh dari tindak pidana kejahatan adalah pencurian yang disebutkan dalam Pasal 362 KUHP. Menurut Kartono (2007), tindak kejahatan bisa dilakukan secara sadar, yaitu dipikirkan, direncanakan dan diarahkan pada satu maksud tertentu secara sadar benar. Namun bisa juga dilakukan setengah sadar, misalnya didorong oleh impulsimpuls yang hebat, didera oleh dorongandorongan paksaan yang sangat kuat 
(kompulsi-kompulsi), dan oleh obsesiobsesi.

Pencurian termasuk kejahatan terhadap harta kekayaan yang unsur-unsurnya adalah mengambil barang orang lain sebagian atau menyeluruh. Pengambilan barang tersebut dengan tujuan untuk memiliki; dan perbuatan mengambil itu dilakukan secara melawan hukum (Moeljatno, 1983). Perlu diketahui bahwa baik Undang-Undang maupun pembentuk Undang- Undang ternyata tidak pernah memberikan sesuatu penjelasan yang dimaksud dengan perbuatan mengambil. Sedangkan menurut pengertian seharihari, kata mengambil itu sendiri mempunyai lebih dari satu arti, yakni: 1) suatu perilaku yang membuat suatu benda berada dalam penguasaannya yang nyata, atau berada di bawah kekuasaanya atau di dalam detensinya, terlepas dari maksudnya tentang apa yang ia inginkan dengan benda tersebut; 2) merupakan suatu tindakan sepihak untuk membuat suatu benda berada dalam penguasaannya (Pasal 362 KUHP, dalam Lamintang, 2009).

Berdasarkan beberapa kasus pencurian yang terjadi, ada sebuah tindakan mengambil barang orang lain secara sembunyi-sembunyi yang berbeda dengan tindakan pencurian biasa. Tindakan tersebut terjadi karena pelakunya memiliki suatu gangguan kendali impuls; gangguan itu disebut kleptomania. Ciri penting dari kleptomania adalah kegagalan berulangkali dalam menahan impuls untuk mencuri benda-benda yang tidak diperlukan untuk pemakaian pribadi atau arti ekonomi (Kaplan dan Sadock, 1997).

Chaplin (dalam Kartono, 2009) mendefinisikan kleptomania dengan suatu impuls obsesif atau kompulsi untuk mencuri. Menurut Grant (2008), kleptomania diartikan sebagai sebuah gangguan yang menonaktifkan impuls kontrol, dicirikan oleh pencurian berulang-ulang dan tidak terkendali terhadap benda- benda yang jarang digunakan oleh orang yang menderitanya.

DSM IV-TR mengklasifikasikan kleptomania kedalam Impulse-Control Disorders Not Elsewhere Classified atau gangguan pengendalian impuls yang tak terklasifikasi dimanapun. Menurut Durrand dan Barlow (2007), gangguan pengendalian impuls, diawali dengan sebuah impuls yang tidak dapat ditolak, biasanya impuls akan sangat merugikan orang yang dikenainya. Gangguan yang termasuk didalamnya sering dimulai dengan godaaan atau keinginan yang destruktif namun sulit ditolak. Ditambahkan Durand dan Barlow,penderita sering dipersepsi oleh masyarakat memiliki masalah itu sematamata karena tidak mempunyai "kemauan".

Kleptomania tidak bisa disamakan dengan tindak pidana pencurian biasa dalam diagnosanya. Kaplan dan Sadock (1997), menyebutkan perbedaan utama kleptomania dan bentuk mencuri lainnya. Pada diagnosis kleptomania, mencuri harus selalu diikuti kegagalan untuk menahan impuls dan harus merupakan tindakan yang tersendiri, dan benda-benda yang dicuri tidak boleh memiliki arti segera atau tujuan keuanganan. Pada mencuri biasa, tindakannya biasanya direncanakan, dan benda-benda yang dicuri untuk digunakan atau memiliki nilai finansial. Kleptomania muncul karena adanya faktor-faktor yang mempengaruhinya.

Psikologi memandang perilaku manusia (human behavior) sebagai reaksi yang dapat bersifat sederhana maupun kompleks. Demikian pula halnya dengan beberapa bentuk perilaku abnormal yang ditunjukan oleh para penderita abnormalitas jiwa ataupun oleh orang- 
orang yang sedang berada dalam ketidaksadaran akibat pengaruh obatobatan, minuman keras, situasi hipnotik, serta situasi-situasi emosional yang sangat menekan (Azwar, 2011). Penelitian ini bertujuan untuk memberikan gambaran mengenai dinamika psikologis individu yang memiliki kecenderungan perilaku pencurian dengan gangguan pengendalian impuls (kleptomania).

Menurut Lamintang dan Lamintang (2009), tindak pidana pencurian diatur dalam bentuk pokok diatur dalam pasal 362 KUHP. Definisi tindak pidana pencurian sendiri adalah mengambil suatu benda yang sebagian atau seluruhnya merupakan kepunyaan orang lain, dengan maksud untuk menguasai benda tersebut secara melawan hukum, karena bersalah melakukan pencurian. Agar seseorang dapat dinyatakan bersalah telah melakukan tindak pidan pencurian, orang tersebut harus terbukti telah memenuhi semua unsur dari tindak pidana pencurian yang terdapat didalam rumusan Pasal 362 KUHP.

Kaplan dan Sadock (1997), menjelaskan bahwa kleptomania sebagai kegagalan rekuren untuk menahan impuls untuk mencuri barang-barang yang tidak diperlukan untuk pemakaian pribadi atau yang memiliki arti ekonomi, benda-benda yang diambil sering kali dibuang, dikembalikan secara rahasia, atau disembunyikan. Orang dengan kleptomania biasanya memiliki uang untuk membayar benda yang mereka curi secara impulsif. kleptomania ditandai oleh ketegangan yang memuncak sebelum tindakan, diikuti oleh pemuasan dan peredaan ketegangan dengan atau tanpa rasa bersalah, penyesalan, atau depresi selama tindakan. Walaupun pencurian tidak terjadi jika kemungkinan akan ditangkap, orang kleptomania tidak selalu mempertimbangkan kemungkinan pe- nangkapan mereka, kendatipun penahanan yang berulang menyebabkan penderitaan dan rasa malu. Orang kleptomania mungkin merasa bersalah dan cemas setela mencuri, tetapi mereka tidak merasa marah atau balas dendam.

Terdapat beberapa kriteria diagnostik kleptomania, diantaranya adalah: 1) kegagalan berulang dalam menolak impuls untuk mencuri benda-benda yang tidak diperlukan untuk keperluan pribadi atau untuk menilai uangnya; 2) meningkatkan rasa ketegangan segera sebelum melakukan pencurian; 3) rasa senang, puas atau lega pada saat bersamaan dengan melakukan pencurian; 4) mencuri tidak dilakukan untuk mengekspresikan kemarahan atau balas dendam dan bukan sebagai respon suatu halusinasi.

Ciri penting dari kleptomania terdiri dari dorongan atau impuls yang rekuren (berulang), intrusive, dan tidak dapat ditahan untuk mencuri benda-benda yang tidak diperlukan. Pasien kleptomania mungkin juga mengalami penderitaan tentang kemungkinan atau sebenarnya mereka memahami dan tanda manifest dari depresi dan kecemasan. Pasien merasa bersalah, malu, dan terhina karena perilaku mereka.

Menurut teori diathesis-stres model terdapat tiga faktor yang menjelaskan munculnya kleptomania, yaitu faktor psikodinamika, faktor biologis, dan faktor psikososial. Faktor psikodinamika menjelaskan bahwa gejala kleptomania cenderung tampak seperti stress yang bermakna sebagai contohnya, kehilangan, perpisahan, dan akhir hubungan yang berarti. Faktor biologis menjelaskan penyakit otak dan retardasi mental telah dihubungkan dengan kleptomania, seperti mereka dihubungkan dengan gangguan pengendalian impuls lainnya. Tanda 
neurologis fokal, atrofi kortikal, dan pembesaran ventrikel lateral telah ditemukan pada beberapa pasien. Gangguan metabolisme monoamine, khususnya serotonin, telah didalilkan. Beberapa peneliti telah menekankan pentingnya aspek psikososial dari gangguan, seperti peristiwa kehidupan awal. Model yang tidak tepat untuk identifikasi dan tokoh orangtua yang sendirinya sulit untuk mengendalikan impuls juga telah diklibatkan.

Kleptomania dapat dimulai pada masa anak-anak, walaupun sebagian besar anak dan remaja yang mencuri tidak menjadi dewasa yang kleptomania. Perjalanan gangguan hilang dan timbul, tetapi gangguan cenderung menjadi kronis. Angka pemulihan spontan tidak diketahui. Gangguan dan komplikasi serius biasanya sekunder karena tertangkap, khususnya jika ditahan. Banyak orang yang tampaknya tidak mempertimbangkan secara sadar kemungkinan harus menghadapi akibat tindakan mereka, suatu ciri yang sejalan dengan penjelasan pasien kleptomania sebagai orang yang merasa disalahkan dan dengan demikian dituduh mencuri. Karena kleptomania yang mencuri adalah jarang, laporan pengobatan cenderung merupakan penjelasan kasus individual atau jumlah kasus yang singkat.

Pada individu pelaku kleptomania, ada keadaan jiwa tertentu sehingga ia terdorong untuk melakukan perbuatan tersebut. Apabila secara klinis bahwa seorang pelaku tindak pidana pencurian terbukti secara sah dan meyakinkan mengidap suatu kelainan jiwa seperti kleptomania dengan pemeriksaan oleh ilmuan yang berkompeten baik itu psikiater atau psikolog, maka tindakan pidana untuk pelakunya dapat batal demi hukum. Hal ini tercantum dalam Pasal 44 ayat 1 yang berbunyi; "Tiada dapat dipidana barang siapa mengerjakan suatu perbuatan yang tidak dapat dipertanggungjawabkan kepadanya, sebab kurang sempurna akal".

\section{METODE}

Pemilihan subjek penelitian disesuaikan dengan tujuan penelitian, yaitu individu yang memiliki kecenderungan perilaku kleptomania. Pemilihan subjek ini mengacu pada kriteria diagnosa yang ditetapkan oleh DSM IV-TR. Berikut adalah karakteristik yang harus terpenuhi pada calon subjek penelitian, yaitu:

1. Berusia antara 20-25 tahun.

2. Memiliki kecenderungan melakukan tindakan mengambil suatu objek secara sembunyi-sembunyi, yang didasari oleh impuls dan pikiran yang berulang-ulang dari dalam diri.

3. Objek yang diambil merupakan benda-benda yang tidak memiliki arti ekonomi.

4. Perilaku masih berlangsung sampai saat penelitian ini dilakukan.

Metode pengambilan data dilakukan dengan metode wawancara semi terstruktur. Gambaran karakteristik kedua subjek dalam penelitian ini disajikan dalam Tabel 1.

\section{HASIL DAN PEMBAHASAN}

Berdasarkan penelitian yang telah dilakukan terhadap kedua subjek, hasil yang didapat adalah perbuatan mengambil barang yang dilakukan oleh subjek secara sembunyi-sembunyi adalah sebagai bagian dari usaha kedua subjek untuk meningkatkan rasa kecemasan dan ketegangan yang akan menghasilkan sensasi ketegangan. Sensasi ketegangan itulah yang dicari dan dinikmati oleh kedua subjek. Rasa puas dan senang dari pengalaman subjek melakukan 
Tabel 1.

Deskripsi Kondisi Subjek

\begin{tabular}{lcc}
\hline Aspek & Subjek 1 & Subjek 2 \\
\hline Jenis Kelamin & Laki-laki & Laki-laki \\
Usia & 24 tahun & 23 tahun \\
Pekerjaan Subjek & - & Mahasiswa \\
Pekerjaan Bapak & Pendidik & PNS \\
Pekerjaan Ibu & Pendidik & Ibu Rumah Tangga \\
\hline
\end{tabular}

Tabel 2.

Unit Makna dan Makna Psikologis Keseluruhan Subjek

\begin{tabular}{lll}
\hline Unit Makna & Makna Psikologis & Subjek \\
\hline Stimulus & Impuls & 1,2 \\
& Repression & 1,2 \\
& Planning & 1,2 \\
External Factors & Crowded & 1 \\
Response & Uncrowded & 2 \\
& Tension & 1 \\
After & Conflict & 2 \\
& Tension reduction & 1 \\
Self-perception & Lack of emphaty & 1 \\
& Conflict & 2 \\
Caught & Pile Up & 1,2 \\
& Subjective & 1,2 \\
Parenting & Caught & 1 \\
& Uncaught & 2 \\
Social & Democratic & 2 \\
& Moral regulation & 1,2 \\
& Religious & 1,2 \\
\hline
\end{tabular}

pengambilan barang secara sembunyisembunyi adalah sebagai pereda ketegangan.

Kedua subjek adalah seorang remaja yang memiliki gangguan pengendalian impuls dengan kecenderungan melakukan kleptomania. Munculnya gangguan itu pada diri kedua subjek telah berlangsung cukup lama, dan frekuensi mereka melakukan perbuatannya pun tidak dapat lagi dihitung dengan angka statistik. Mereka melakukan kleptomania karena didorong oleh suatu impuls ketika melihat sebuah objek yang berperan sebagai stimulus. Terkadang untuk melancarkan aksinya, kedua subjek melakukan beberapa perencanaan. Perencanaan dilakukan untuk melakukan pengamatan singkat mengenai situasi dan kondisi sekitar objek berada. Hal ini dilakukan untuk memastikan keamanan. Mereka tidak ingin mendapat resiko buruk akibat perbuatan mereka. Pada subejk 1, situasi yang ideal menurutnya adalah crowded atau situasi sekitar yang 
ramai. Menurutnya, dalam situasi seperti itu perhatian orang-orang disekitarnya akan teralihkan dan tidak terfokus pada barang-barang yang ada disekitarnya. Hal ini juga berlaku disebuah took atau tempat perbelanjaan, dimana situasi ramai dapat mengalihkan perhatian para penjaganya. Berbeda dengan subjek 1, subjek 2 memilih uncrowded atau situasi sepi sebagai tempat yang ideal untuk menjalankan aksinya. Situasi seperti ini dipilih, karena dirinya menghindari keungkinan buruk terjadinya penangkapan apabila ada orang lain yang melihat gerak-geriknya.

Ketika melakukan perbuatannya, subjek 1 merasakan tension atau perasaan tegang. Perasaan tegang tersebut dihasilkan karena dirinya menyadari sedang melakukan perbuatan yang buruk. Namun, bagi subjek 1 perasaan tegang yang muncul tidak membuatnya merasa terganggua. Dirinya justru menikmati perasaan tegang tersebut dan menganggapnya sebagai sebuah motivasi untuk segera menyelesaikan perbuatannya. Pada subjek 2, ketika melakukan perbuatannya, justru konflik yang didapatkannya. Konflik ini dihasilkan karena ada pertentangan antara keinginan dan perasaan bersalah dan berdosa. Untuk mengatasi konflik yang muncul, maka dirinya akan mempercepat proses pengambilan objek. Karena apabila konflik tersebut membesar, maka hal itu akan membuat keyakinannya melemah dan membuatnya mengurungkan niatannnya.

\section{KESIMPULAN}

Makna dari sebuah tindak pencurian adalah suatu tindakan pengambilan barang orang lain dengan tujuan untuk memilikinya. Secara harfiah, hal ini sama dengan makna pada kecenderungan kleptomania. Unsur dari perbuatan kleptomania juga merupakan sebuah tindakan untuk melakukan pengambilan barang dengan tujuan untuk memilikinya. Namun, pembeda keduanya hanya pada motif, jenis barang, dan perlakuan terhadap barang selanjutnya. Jika, pada pencurian biasa pelakunya selalu berdasarkan motif ekonomi, namun pada kleptomania tindakan yang dilakukan sebagai pemenuhan kepuasan diri dan sebagai cara untuk memenuhi dorongan yang muncul ketika melihat suatu objek.

Para pelaku kleptomania, mengambil barang-barang dan lalu mengumpulkannya disebuah tempat. Para pelaku kleptomania, pada dasarnya tidak tertarik untuk menjual barang-barang mereka. Namun, apabila ada faktor yang menguatkan, hal itu bisa saja terjadi seperti contohnya adalah ketika ada orang yang tertarik pada barang yang dimiliki oleh pelaku kleptomania, dan ingin memilikinya.

Bagi peneliti lain yang tertarik dalam penelitian yang sama, diharapkan lebih mengembangkan dan menyempurnakan penelitian ini. Banyak dunia kehidupan pelaku kecenderungan kleptomania yang belum terungkap dalam penelitian ini, untuk itulah peran peneliti lain dalam penelitian serupa sangat diharapkan agar terciptanya penelitian serupa yang lebih kompleks mengangkat dunia kehidupan para pelakunya. 


\section{DAFTAR PUSTAKA}

American Psychiatric Association. (2000). Diagnostic and Statistical Manual of Mental Disorders. 4th ed., Text Revision (DSM IV-TR) Washington (DC): American Psychiatric Publishing, Inc.

Azwar, S. (2011). Sikap Manusia. Teori dan Pengukurannya edisi 2. Yogyakarta: Pustaka Pelajar.

Grant, J. E. (2008). Kleptomania: Clinical characteristics and treatment. Department of Psychiatry University of Minnesota School of Medicine.

Kaplan, H. I., Sadock, B. J., \& Grebb, J. A. (1997). Sinopsis Psikiatri, edisi ke-tujuh jilid dua. Jakarta: Binarupa Aksara.
Kartono, K. (2009). Kamus Lengkap Psikologi. Jakarta: Raja Grafindo Persada.

Kartono, K. (2007). Patologi Sosial 1. Jakarta: Raja Grafindo Persada.

Lamintang, P. A. F. \& Lamintang, T. (2009). Delik-delik khusus kejahatan terhadap harta kekayaan. Jakarta: Sinar Grafika.

Moeljatno. (1983). Perbuatan pidana dan pertanggung jawaban dalam hukum pidana. Jakarta: Bina Aksara.

Prayudi, G. (2008). Seluk beluk hukum pidana yang penting untuk diketahui. Jakarta: Boya Book. 